\title{
Facilitated extinction of an avoidance response through shortening of the inter-trial interval
}

\section{DAVID OLER AND MORRIE BAUM, DEPARTMENT OF PSYCHOLOGY, MCGILL UNIVERSITY, Montreal, Canada}

Female albino rats were trained to avoid shock by jumping onto a ledge in an automated avoidance box. All animals received training with an intertrial interval (ITI) of $30 \mathrm{sec}$. After attaining a learning criterion of 10 consecutive avoidances, the shocker was disconnected and extinction trials began. Group $C(N=9)$, a control group. continued to receive an ITI of $30 \mathrm{sec}$ during extinction. Group $I(N=9)$ received an ITI of 6 sec and Group 2 $(N=9)$ an ITI of 54 sec during extinction. Rats in Group 1 extinguished in significantly fewer trials than did those of either of the other two groups. All animals showed virtually no spontaneous recovery of the response one day later.

Some previous research has indicated that shortening of the intertrial interval (ITI) can hasten the extinction of an avoidance response in rats. Edmonson \& Amsel (1954) found that massing of trials facilitated extinction of an avoidance response, but the response showed great spontaneous recovery the following day. They interpreted their results in terms of Hull's notion of reactive or work-produced inhibition. Due to the frequently-noted high resistance to extinction of avoidance responding and its analogy in persistent, anxiety-motivated behavior in man, any technique which can hasten extinction is of importance. The present study sought to further investigate the facilitated extinction of an avoidance response through shortening of the ITI.

Subjects. Thirty-one experimentally naive female albino rats obtained from the Canadian Breeding Farm and weighing between 185 and $220 \mathrm{~g}$ served as Ss. They were housed in group cages with food and water constantly available.

Apparatus. The apparatus used was entirely automated and was the same as that described extensively in previous studies (Baum, 1965, 1966). Briefly, it consisted of a large plywood and Plexiglas box fitted with a grid floor through which scrambled electric shock could be administered (115 V ac through a $100 \mathrm{~K}$ resistor in series with $S$ ). Into one side of the cube-shaped box projected a 2-1/2 in.-wide safety ledge.The rat could escape or avoid shock by jumping or climbing onto the ledge, where its presence was detected by a photocell system. The safety ledge was automatically retractable (via an electric motor device) and a quick retraction of the ledge resulted in the rat's falling to the grid floor.

Procedure. Without prior habituation to the apparatus, each rat was dropped onto the grid floor via the sliding ceiling. Ten sec after the rat had landed on the grid, the grid was electrified and $S$ received foot-shock until it escaped by jumping or climbing onto the safety ledge. The rat was allowed to remain on the ledge for $30 \mathrm{sec}$ (the ITI), after which the ledge was automatically retracted, causing $S$ to fall to the grid floor and thus initiating the next training trial. Throughout training, the rat was permitted to avoid receiving shock by jumping or climbing onto the ledge within $10 \mathrm{sec}$ of having been knocked down onto the grid. Each rat was trained until it attained a learning criterion of 10 consecutive avoidance responses.

Immediately after $\mathbf{S}$ attained the learning criterion, the shocker was disconnected by $E$ and the extinction procedure began. Extinction varied for three different groups. Each $S$ in Group $1(N=9)$ was given a 6-sec ITI on the safety ledge during extinction. Those in Group $2(\mathrm{~N}=9)$ were aliowed a $54 \mathrm{sec}$ ITI while $S s$ in Group $C(N=9)$ received an ITI of 30 sec during extinction. Thus the ITI for Groups 1 and 2 was 24 sec shorter and longer, respectively, than it had been during acquisition, while Group C, the control group, had the same ITI throughout. Each $S$ in the three groups was run until it attained an extinction criterion of five consecutive min on the grid floor without responding, or until it made 100 responses.

After extinction, all Ss were returned to their home cages for $24 \mathrm{~h}$, following which those Ss which had attained the extinction criterion were again dropped onto the grid floor of the apparatus to test for the spontaneous recovery of the avoidance response. During spontaneous recovery testing, the ITI was $30 \mathrm{sec}$ for all groups. A fourth group, Group $\mathrm{Cl}(\mathrm{N}=4)$ underwent the same training procedure as did the other three groups. However, after attaining the learning criterion, $\mathrm{Ss}$ in Group $\mathrm{Cl}$ were removed from the apparatus and returned to their home cages without undergoing extinction. After $24 \mathrm{~h}$ had elapsed, these Ss were again dropped onto the grid floor of the apparatus (with the shocker disconnected), in order to see if the avoidance response persisted over a one day period if no extinction was given.

Results. The acquisition, extinction, and spontaneous recovery data for the three major groups are summarized in Table 1. All of the groups performed similarly in acquisition, and there were no significant acquisition effects. In extinction, Ss in Group 1 (shortened ITI) extinguished in significantly fewer trials than did those in either Group $2(U=5, p<.002)$ or Group $C(U=8$, $\mathrm{p}<.02$ ). There was no significant difference between Groups $\mathrm{C}$ and $2\left(\mathrm{U}=32 \frac{1}{2}, \mathrm{p}>.10\right)$. Except for one animal in Group $\mathrm{C}$, all rats attained the extinction criterion in less than 100 trials. In spontaneous recovery testing, the three groups which underwent extinction made virtually no responses, as indicated in Table 1. No rat in either of these three groups made more than two responses in spontaneous recovery, and most $(22 / 26)$ made no responses whatsoever but rather re-attained the extinction criterion upon being placed in the apparatus. All four Ss in Group $\mathrm{Cl}$ made more responses than any of the extinguished animals on the day following training $(U=0, p<.02)$, showing that the absence of spontaneous recovery was not simply due to a foregetting of the response over the one-day waiting period. All of the above statistical comparisons made use of a two-tailed Mann-Whitney U-test.

Discussion. The present study confirms that shortening of the ITI or massing of trials hastens the extinction of an avoidance response in rats. However, unlike Edmonson \& Amsel (1954), we found no spontaneous recovery of the response the next day, a finding which argues against a work-inhibition interpretation of the results. The lack of spontaneous recovery may be attributable to the stiff extinction criterion employed or to the fact that the avoidance response had been very rapidly learned, rather than being slowly acquired over numerous training days.

Apart from the work-inhibition analysis, several other theoretical arguments could be advanced to account for the results obtained in this study. The generalization-decrement theory of extinction, which has been used to explain some results of avoidance extinction (e.g., Hall, 1955), would maintain that the ITI was part of the stimulus complex which controlled the avoidance response in acquisition. Thus any change in ITI would hasten extinction through greater generalization decrement. This would account for the finding that the shortened ITI facilitated extinction, but it would also predict that a lengthening of the ITI would also hasten extinction, which is contrary to the results obtained. Lengthening the ITI in our study produced, if anything, an increased resistance to extinction of the response (although the increase was not significant).

The results of this study can be explained in terms of "elicitation theory," which emphasizes the reinforcing properties of the ITI in avoidance responding (Denny \& Adeiman, 1956: Weisman \& Denny, 1963; Weisman et al, 1966). According to this view, the ITI in avoidance training provides the

Table 1

\begin{tabular}{|c|c|c|c|c|}
\hline & $\begin{array}{c}\text { Group C } \\
(n=9)\end{array}$ & $\begin{array}{c}\text { Group } 1 \\
(n=9)\end{array}$ & $\begin{array}{c}\text { Group } 2 \\
(n=9)\end{array}$ & $\begin{array}{l}\text { Kruskal- } \\
\text { Wallis H }\end{array}$ \\
\hline $\begin{array}{l}\text { Mean number of shocks } \\
\text { received in acquisition }\end{array}$ & 4.2 & 5.7 & 5.9 & $2.80, \mathrm{~ns}$ \\
\hline Mean trial of the tenth & 15.7 & 21.1 & 19.2 & $4.56, \mathrm{~ns}$ \\
\hline
\end{tabular}

consecutive avoidance in acquisition

Mean number of responses 49.4 in 100 extinction trials

Mean number of responses in spontaneous recovery

$\begin{array}{lll}0.2 & 0.2 & 0.28, \mathrm{~ns}\end{array}$


opportunity for the animal to groom, explore, and otherwise relax following the termination of the aversive stimulus, and thus the ITI period of safety comes to serve as a positive incentive for the avoidance response to occur. The longer the ITI the greater the reward for avoiding, and in extinction the longer ITIs should sustain avoidance responding more than shorter ones. A weakness of this analysis is that elicitation theorists posit that an ITI of 150 $\mathrm{sec}$ or longer is necessary for relaxation to occur following the termination of a conditioned or unconditioned aversive stimulus, while the effect obtained in this study involved appreciably shorter ITIs.

Yet another explanation of the results may be that massed trials result in the frequent presentation or onset of the fear CS (being knocked onto the grid floor in this study). This may be more aversive and more fear-provoking than exposure to the CS for a protracted period of time. Thus, when extinction trials are massed, the rat is faced with an avoidance-avoidance conflict which it resolves by preferring exposure to the protracted CS, thus attaining the extinction criterion sooner.

Apart from theoretical considerations, the present study demonstrates that shortening of the ITI facilitates extinction of the avoidance response and that, under the conditions employed, no spontaneous recovery of the response occurs. Further experiments are planned to fully evaluate this technique as a means for hastening extinction, and to compare it to response prevention or flooding which has also been found to be effective in hastening the extinction of avoidance responding in the same experimental situation (Baum, 1966, 1968).

\section{REFERENCES}

BAUM, M. An automated apparatus for the avoidance training of rats. Psychol. Rep., 1965, 16, 1205-1211.
BAUM, M. Rapid extinction of an avoidance response following a period of response prevention in the avoidance apparatus. Psychol Rep., 1966, 18, 59-64.

BAUM, M. Efficacy of response prevention (flooding) in facilitating the extinction of an avoidance response in rats: The effect of overtraining the response. Behav. Res. Therapy, in press.

DENNY, M. R., \& ADELMAN, H. M. Elicitation theory: II. The formal theory and its applicafion to instrumental escape and avoidance conditioning. Unpublished theoretical paper, Michigan State University, 1956.

EDMONSON, B. W., \& AMSEL, A. The effects of massing and distribution of extinction trials on the persistance of a fear-motivated instrumental response. J. comp. physiol. Pyychol, 1954, 47, 117-123.

HALL, J. F. Experimental extinction as a function of altered stimulating conditions. J. genet. Psychol, 1955, 87, 155-158.

WEISMAN, R. G. , \& DENNY, M. R. The reinforcing properties of the intertrial interval in conditioned avoidance. Paper read at the Midwestern Psychological Association meeting, Chicago, Ill., 1963.

WEISMAN, R. G., DENNY, M. R., PLATT, S. A., \& ZERBOLIO, D. J., Jr. Facilitation of extinction by a stimulus associated with long nonshock confinement periods. J. comp. physiol PsychoL, 1966, 62, 26-30.

\section{NOTES}

1. This research was supported by Grant No. APA-253 to Morrie Baum from the National Research Council of Canada.

2. The authors are indebted to George C. Croswell of the University of Pennsylvania for his expert construction of the apparatus. 